away by acrid or irritating secretions. We can initate this condition of the parts by the slight application of the nitrate of silver--sufficient to affect the epithelial covering, but not sufficient to injure the mucous membrane beneath.

It appears to me that we can neither receive the existence of excoriation or abrasion; of granulation or fungous growths; the secretion of pus or muco-purulent matter; as affording undeniable evidence of the existence of "nlceration" of the os and cervix uteri. We must try ulceration in this part of the body by the same tests which we apply to ulcers in other parts of the economy. We must look for a solution of continuity, with a secreting surface, separated from the healthy structures, having defined edges, everted or inverted,-for an ulcer, in fact, in the common pathological meaning of the term. We find ulcers having these characters in the air-passages, mouth, stomach, intestines, bladder, and other mucous surfaces. There is no mistaking the characters of an intestinal ulcer after dysentery, and there ought to be no mistake about an ulcer of the uterus. Indeed, in the corroding ulcer of the uterus we unfortunately see that this organ is but too capable of taking on all the qualities of ulceration, in a degree only equalled by its extraordinary vitality, the organ being scooped out, or eaten away, in a comparatively short space of time. Cases are also met with, in which the os uteri has been destroyed by the sloughing ulceration, and loss of structure, sometimes following the application of the more powerful caustic agents. We are, how ever, called upon, by the unlimited believers in uterine ulceration, to admit that ulcerative disease may exist for years, in its common form, without any perforation, excoriation, serious loss of substance, or altered configuration. Whether we test the so-called ulceration of the uterus by ulceration occurring in other mucous surfaces, or in the nterus itself, under undoubtedly nlcerative disease, the distinctive characteristics are wanting in the great majority of cases; and they certainly are not found, unless I am most egregionsly mistaken, in the enormous proportion of 222 cases of ulceration to 300 cases of promiscuous uterine disease.

In all that I liave said, I do not wish it to be supposed that I question the frequency of irritation, chronic inflammation, and subacute inflammation, in connexion with leucorrhœa. Recent writers would, however, treat leucorrhoa merely and solely as a symptom, not as an independent disorder. But I am well assured that it is often the disease itself, or at least all of it that we can appreciate; and that the irritable or inflammatory condition is excited secondarily, and mainly, by the morbid leucorrhcal secretion. Some change in the innervation or nutrition of the organ occurs; or it sympathizes with a malady in some remote organ, and the secretions are consequently depraved. These depraved secretions irritate the surfaces with which they come in contact, and produce the visible signs of irritation or inflammatory action. We see these discharges sometimes inflame and excoriate even the external integument, but we should never dream of saying that the inflamed condition of the skin was the essential part of the disorder. The same observation applies to the uterus. Thus it is not pathological, nor useful, always to consider leucorrhoea as a mere symptom; and the old plan of astringent injections, though sometimes michievous, cannot quite be dispensed with, for in some, even profuse leucorrhoeas, an astringent injection, by arresting the utero-vaginal discharges, does more than any other plan to soothe inflammatory conditions, or rather, to suspend their causes.

Nothwithstanding the use of the speculum,-notwithstanding the use of lamps and glasses, there is often considerable difficulty in ascertaining the precise condition of the cavity of the uterine cervix, engorged as it is, and deep in colour from irritation, or other disease, and from the interruption to the circulation in the uterine organs which is almost necessarily dependent on the introduction and expansion of the speculum within the vagina. But in the dead subject no such difficulties exist, and it might certainly be expected, since leucorrhoa is a malady so very common, that uterine ulceration would be frequentiy revealed by post-mortem examinations. The only place in which, so far as I am aware, post-mortem examinations have been conducted in considerable numbers, with special reference to the determination of the frequency or infrequency of ulceration of the os and cervix uteri, is at St. George's Hospital. For several years past, the condition of the uterus has been examined with great minuteness and accuracy in the dead subject at this hospital.

Mr. Pollock, one of the lecturers on Anatomy at St. George's Hospital, informs me, that for more than three years during which he was Curator to the hospital museum he examined the uterus internally and externally, in all the subjects in the dead-house. During this time, upwards of 100 women died in the hospital annually. In each case, the uterus was laid open, and carefully inspected. Mr. Pollock only detected actual and uumistakable ulceration in four cases. Of these, three were scrofulous subjects, and scrofulons ulceration existed in other parts of the body; and in one of them the ulceration involved the vagina extensively as well as the os uteri.

Mr. Gray, who succeeded Mr. Pollock as Curator, informs me that during his curatorship he examined the bodies of 180 women, who had died of all diseases in St. George's Hospital, with a distinct view to ascertain the proportion of cases in which ulceration of the uterus existed. These examinations were also conducted with great care and minuteness. Out of the 180 subjects, distinct ulceration of the os and cervix was found in only three instances. Slight abrasions, discolourations, and granulations were frequently observed, and this accords with the observations of Mr. Pollock. One or two other curators to St. George's Hospital, besides Mr. Pollock and Mr. Gray, have arrived at the same results. It is only by pathological investigations of this kind that we can arrive at infallible results.

But, it may be asked, why bestow so much pains on proving that abrasion, excoriation, and ulceration are not ulceration? Why dispute as to terms? Simply because a name rules treatment, and becanse the name of "vlceration" being first given, an heroical treatment, not without danger, is frequently resorted to where milder local applications or constitutional treatment would be equally efficacious. After Mr. Abernethy wrote his celebrated work on the Constitutional Treatment of Local Disease, his idea was pushed to its extreme, and local remedies were often most improperly neglected. Now, in all that relates to the uterine organs, the doctrines of $\mathrm{Mr}$. Abernethy are in danger of being entirely refuted, and we are in some risk of utterly neglecting constitutional treatment, and of being entirely absorbed by local applications. This we cannot do without impeding the improvement of the treatment of this class of affections. When a patient is told she has an ulceration of the womb, she often thinks of an ulcer of the leg, or the cheek, \&c., and is proportionably frightened, because of the importance of the organ which is the seat of the presumed disease. There is nothing women will not submit to to be freed from such a dire malady. At the present time a veritable nterine panic affects the upper and middle classes of society, and every woman with the slightest ache, or discharge, is not satisfied until the peccant organ has been ocularly inspected. I do not believe that this state of things, or its inevitable results, will conduce to the dignity and respectability of our profession. I do not hesitate to affirm, so far as I have eyes to observe and a judgment to weigh facts, that much exaggeration prevails respecting the frequency of this same ulceration of the os and cervix uteri-an exaggeration which should be calmed, so that the legitimate methods of examination may lead, not to a suspicion of our profession, but to real improvement in the diagnosis and treatment of uterine disease as it actually exists. We cannot safely repudiate either the local or the constitutional treatment of uterine disease. I have seen cases in which the local ailments has been as far as possible cured; nevertheless, the constitutional symptoms remained unrelieved. I have seen others, in which judicious constitutional treatment has cured the local malady without any topical treatment whatever. But in the combat against disease, we require both constitutional and local weapons; and any views which disparage either the one or the other, must cripple the resources of our art.

\section{CASES OF SPINA BIFIDA.}

\section{Bx WILLIAM T. ILIFF, Jun., Ese., London.}

THE operation in a case of spina bifida, recorded in THe LANCET of February 23, p. 246, recals to my mind three cases I treated some years ago, whilst dresser at Guy's, and the progress of which Mr. Hilton kindly watched with me: the notes of them, including the account of the fluid drawn off on the different occasions, were furnished to him, and I regret that, owing to his not having been able to lay hands on them, the cases are not quite complete.

CASE 1.-Martha M- aged one month, was brought to me, with a tumour in the mesian line of the lumbar region containing fluid, and with the skin over it, attenuated shiny, and somewhat injected, it was in size about half a small apple; has increased rapidly, and could be slightly reduced by pressure; the child appeared healthy, and there was no paralysis. 
Two years ago, the mother was confined of a boy; he had congenital hernia. Her labour this time was bad, and instru. ments required. I tapped it eight or nine times, at intervals of three or four days, without ill effect, and with the good result of the gradual diminution in size of the sac, and a more healthy colour and consistence of the skin, and at length there remained a slight, firm, almost hard elevation, of no great extent, and uninfluenced either by external pressure or straining efforts of the child. She was seen by me, off and on, for some months, and continued perfectly well.

CASE 2.- H- H_- aged one month, was brought to me in March, 1844, a year or two after the former case; a delicate, spare infant, one of six children; mother weak; it is, however, very hearty in sucking; no complete paralysis, but deficient motive power of the lower extremities, the legs being little moved, and almost always crossed. In the lumbar region was a swelling, of similar appearance and size to Case 1 , but the skin was more tense. I tapped it three or four times, without any apparent ill effect; once a little blood only followed; the parents afterwards ceased to bring it, whether from death or not I never could learn.

CASE 3.-Catherine M_- the child of healthy parents, residing in Bear-lane, Blackfriars-road, was born February 13th, 1844, and brought to me on the 7 th of March. The mother had a severe fall when eight months gone, and attributes the malformation (erroneously, of course) to this. The infant sucks well; is rather restless, and always keeps its legs drawn up, nor have they ever been straight, though the mother has tried gently to extend them; there is very little motive power in them; most in the left; their size is natural; a similar swelling to the other cases is visible, quite low down in the lumbo-sacral region; the skin in the centre bluish and atte nuated. I tapped it, and again on the 11th; I then drew off six drachms of clear fluid. On the 14th, the fluid was thicker. On the 18th and 21 st, the sac was quite emptied, the parietes flaccid, and the child more lively and less restless. The operation was repeated on the 25 th, 28 th, and April 1st; the in fant, however, became more restless, hiccongh was set up, and she died in quite the early part of April. On no occasion could any increase of symptoms be traced to the tapping. The body was examined by Mr. Hilton and myself, and it was found that the cord and nerves were spread out over the posterior wall of the sac, but did not appear to have re. ceived any injury.

In all the cases the operation was performed in the mesian line inferiorly, and Dr. Babington's fine trocar was used. The infant was laid on its belly with the head a little depending; and scarcely any pressure was used to encourage the flow of fluid. A small piece of strapping was then applied, and over it a pad of lint, with a long strip of plaster crossed and recrossed, so as to give support, but not pressure. A little compound soda powder was given when the children were restless, and in the last case, towards the end, mercury with chalk and Dover's powder, \&c. It must be allowed, I think, that the cases, though not completely satisfactory, are yet encouraging rather than otherwise; and in the first case I have every reason to anticipate a favourable progress. After it ceased to come under my notice, great care was taken of it, so that no injury should accrue to the shrivelled sac, and the child at the end of some few months from the last operation was well.

The last case, to my mind, presents a most decided reason against the operation by the ligature, as the spinal cord was intimately connected with the sac - a fact which during life could not be detected. Nor is this an isolated case; all authors refer to such; for it is a disease well known, though rare. I may here perhaps quote briefiy three cases recorded by Tulpius* as not without interest. The first case, when born, had a large tumour on the loins, and on its being opened much water escaped, and with it the life of the child. The fluid having been removed, the vertebra were remarked as it were rent, so far apart also, and the nerves of the medulla spinalis so blended with the parietes of the tumour itself, that there was hardly a spot where the knife could have been introduced without peril to the life of the infant. It happened to him not long after to see a similar tumour, but it was ruptured in parturition, the infant only surviving three days, owing, on the one hand, to gangrene attacking the sides of the ruptured sac, and on the other to the changes produced in the exposed nerves by atmospheric contact. In the third case, the pedicle was somewhat narrow; and the surgeon, with a view to its removal, applied a very tight ligature round it, intending to

\footnotetext{
* Nicol Tulpii Observationes Medicæ, Editio Quinta, p. 229.
}

cut off the sac when its vitality was destroyed; but before this happened the infant died. It was found that the medulla spinalis was lacerated, and the nervous branches so irregularly scattered through the tumour, that it lay beyond the power of surgery to remove it without also destroying life. An engraving is given of the post-mortem appearances. He speaks also of having seen six cases of this disease.

Puncturing in the mesian line, I am aware, is decidedly opposed by Mr. P. Hewett, on the ground that at this point the cord and its nerves are generally connected with the sac, and very possibly this may be the case. In the one, however I examined, its safest spot was in the mesian line, and not at the side.

In conclusion, I cannot but refer to a most interesting case by Mr. C. Hawthorn, of Sandon, which will well repay careful perusal, and may be justly regarded as an example of sound and successful surgical treatment of this interesting disease (See The Lancet, Nov. 28, 1846, p. 582.)

ON THE

\section{EFFECTS AND TREATMENT OF INJURIES ARISING FROM THE INHALATION OF THE FOUL AIR OF SEWERS, ETC.}

\section{By W. JAMES KITE, EsQ., M.R.C.S., L.S.A.}

CASE 1.-Oct. 11th, 1847: a man, aged twenty-seven, generally enjoying good health, was employed with another (Case 2) to clean out a cesspool, fourteen feet in depth, and proportionately wide, which received the sewage of a house, containing a family, and a large number of domestics, and which had not been open for some time, and into which, previously, had been thrown a quantity of sulphuric acid, with the supposed intention of rendering the efluvium proceeding from it innocuous. During the effervescence caused by this procedure, this man entered the cesspool, and was imme diately rendered insensible, and fell. In the space of about ten minutes he was extricated from his dangerous position, and on being brought into the open air, presented the following symptoms:-Perfect insensibility; apparently not breath ing; extremities cold.

The first sign of life soon appeared, in the gasping for breath, which, irregular at first, shortly became more frequent and regular. A warm bath, friction to the surface of the body generally, and warm brandy-and-water, were the first remedies. - At eleven A.M., half an hour after the occurrence of the accident, he was still insensible; was rolling his body from side to side, breathing loudly; face pallid; eyelids closed; pupils sensible, dilated; skin perspiring; feet cold; pulse very quick and feeble; deglutition perfect, but the jaws firmly clenched. Ether and aromatic spirit of am. mouia, of each, twenty minims, were given, in warm brandy. and-water; was again ordered into a hot bath; frictions to extremities employed at same time; the stimuli to be repeated every twenty minutes, or according to circumstances.-Two P.M.: Frictions to the extremities, and the application of heat, with mustard cataplasms to the calves of the legs, have been the means employed, in addition to the exhibition of stimulants. He occasionally appears to be sensible, then relapses; is restless; extremities warm; pulse not so frequent, and firm; conjunctivæ injected; abdomen tympanitic, resonant. Ordered a turpentine enema; the stimulants to be repeated occasionally.-Seven P.M.: Sensibility is in a great measure restored. On being questioned, says he is better, and very thirsty; sits up, and swallows gruel; the surface of the skin generally is warm and perspiring; eyes intolerant of light stiff and sore; pulse ninety-six, soft and regular. A saline, draught, with ammonia, to be given occasionally; broth diet, with gruel.

Oct. 12th.-Six A.M.: Has slept soundly during the night; complains of an intense headach, stiffness of the body and soreness of the eyes; the conjunctivæ much injected, and secreting a purulent discharge; the cornea of the right eye is opaque; skin warm, pulse regular, not quick; reaction is not excessive; bowels have not been relieved. A saline aperient draught every three hours. Broth diet.-Eight P.M.: Has been sleeping much during the day; breathing stertorously; complains much of pain in head and eyes; head hot; pupils dilated; bowels have been relieved. Continue as before, with cold lotion to the head. 